\title{
Point in Time Date and Time Data Type
}

National Cancer Institute

\section{Source}

National Cancer Institute. Point in Time Date and Time Data Type. NCI Thesaurus. Code C95678.

A data type comprised of a date and time value that corresponds with a specific point in the time continuum. 